\title{
Offering Patients a Medical Home - Not a Hallway - and a Stronger Health System
}

Leanne Clarke and Kavita Mehta on behalf of the Ontario College of Family Physicians and Association of Family Health Teams of Ontario

\begin{abstract}
This article examines three family health teams (FHTs) in different Ontario communities that exemplify the features of a Patient's Medical Home (PMH), a vision developed by the College of Family Physicians of Canada. With PMH supports and foundations in place, these FHTs deliver highquality care enabled by strong PMH functions: accessible, comprehensive, patient- and family-centred continuous care that is responsive to a community's unique needs. Adhering to $\mathrm{PMH}$ principles not only improves patient experience, health outcomes and provider satisfaction but also leads to fewer unnecessary hospital admissions and emergency room visits - system savings and better use of public resources.
\end{abstract}

\section{Introduction}

The Ontario FHTs featured herein are from decidedly disparate places: northern rural Marathon, small-city Peterborough and Markham in the Greater Toronto Area. They serve different populations and face distinct challenges. But they all display hallmarks of a shared vision of the ideal family practice in Canada: a Patient's Medical Home (PMH).

With that vision realized, patients interact with familiar, trusted physicians and health teams throughout their lives and receive the kind of help and quality of care that meet their multiple needs and make them feel at home, confident their health is in good hands. Not incidentally, a fully implemented PMH vision is also the linchpin of a highperforming, integrated, sustainable health system, a system without a need, or sign, of hallway medicine (Aggarwal and Hutchison 2012).

The College of Family Physicians of Canada developed the $\mathrm{PMH}$ in 2011, modelling it on the US Patient-Centred Medical Home. Recently refined, the $\mathrm{PMH}$ family practice vision is built on three elements, listed below, that augment the original pillars (Figure 1).

\section{Foundations}

Foundation pillars underpin a practice's ability to deliver highquality, patient-centred care, providing the following:

- appropriate infrastructure (e.g., human resources, electronic records and other digital supports);

- administration and funding (e.g., financial/governmental support, strong governance and leadership); and

- connected care (practice integrated with other settings via health technology). 
FIGURE 1.

\section{The Patient's Medical Home}

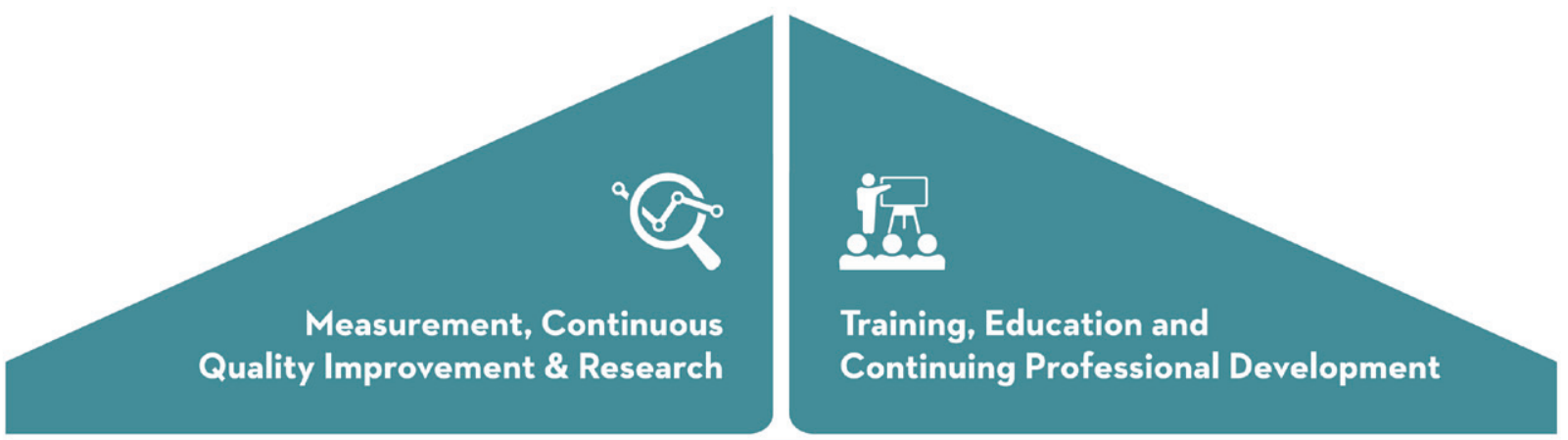

\section{ONGOING DEVELOPMENT}
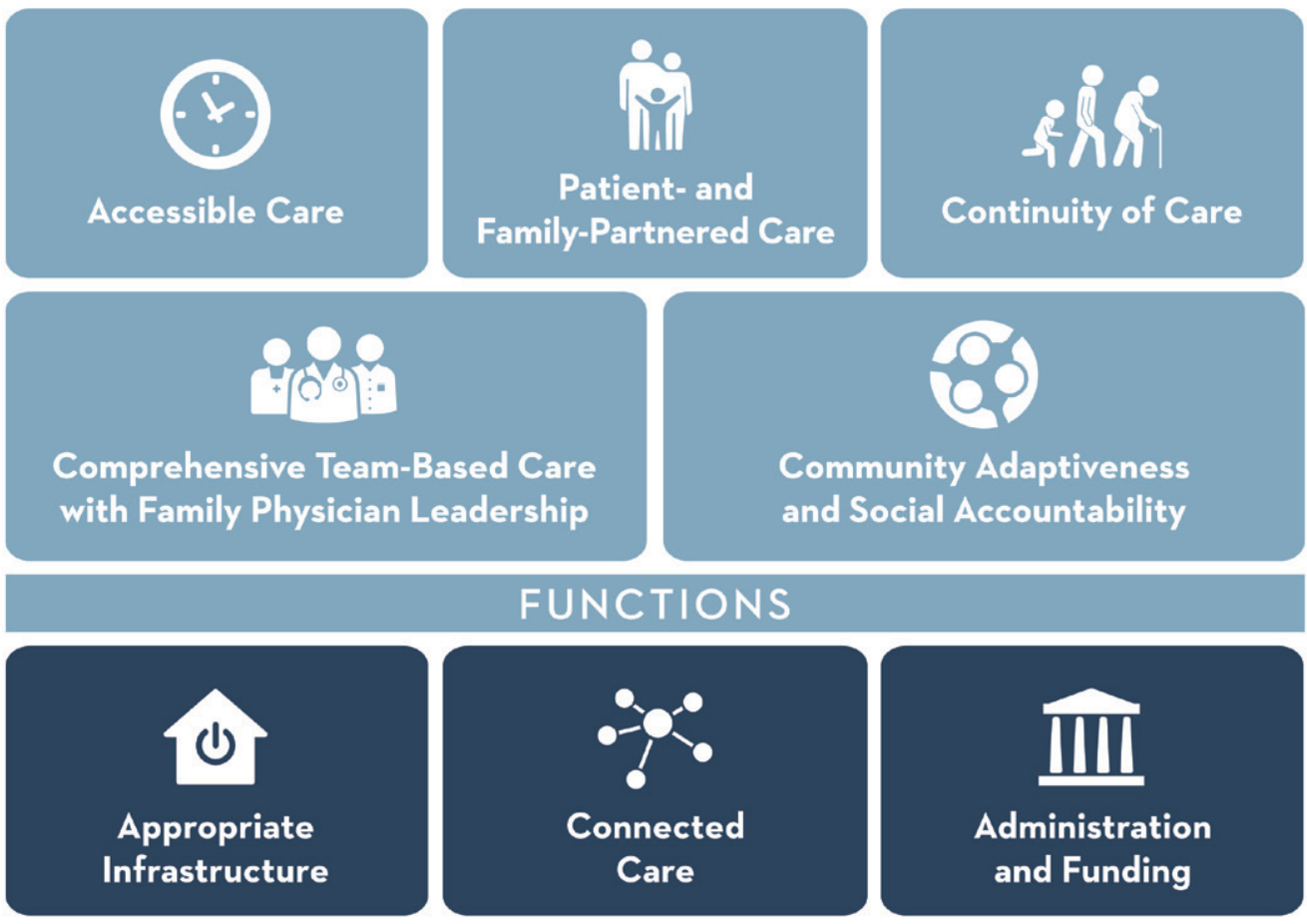

\section{FUNCTIONS}
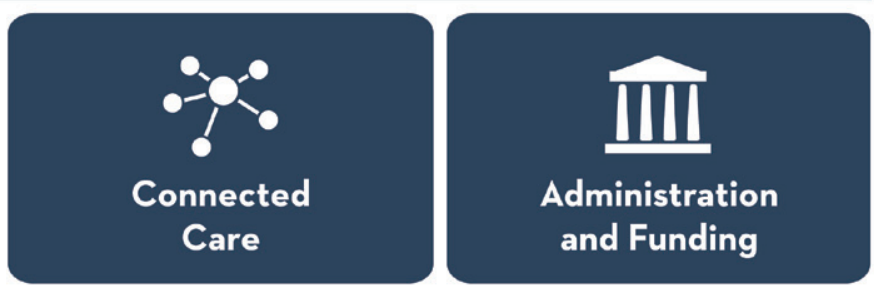

\section{FOUNDATIONS}

\section{Functions}

$\mathrm{PMH}$ functions are prerequisites for delivering care that is:

- accessible;

- grounded in the continuity of a relationship with a family physician or nurse practitioner (NP);

- patient and family centred;

- comprehensive and team based with family physician leadership; and

- accountable to the community and responsive to patients' social environments and conditions.

\section{Ongoing Development}

A PMH practice proactively and persistently strengthens those functions through the following:

- measurement, continuous quality improvement (QI) and research; and

- training, education and continuous professional development.

\section{Patient's Medical Home}

These elements are both essential and beneficial to strengthening primary care outcomes (Starfield et al. 2005). They are 
more than concepts; reforms in provinces such as British Columbia and Alberta are translating PMH theory into practice to address health system challenges (Cavers et al. 2010; College of Family Physicians of Canada 2011; Katz et al. 2017; MacCarthy and Hollander 2014).

On-the-ground examples of PMH principles at work in Ontario are featured below in three high-performing FHTs, a model of interprofessional team-based primary care introduced in 2005. While all these practices are FHTs, the PMH principles can be applied to any practice, regardless of model.

Marathon's FHT shows the power and impact of integrated, collaborative team-based care to improve opioid prescribing. The Markham FHT keeps patients with eating disorders medically stable while awaiting specialized treatment, filling a service gap through comprehensive interprofessional teambased care. In Peterborough's FHT, two new clinics targeted to residents without a family physician tackle access problems through virtual and rural-based care.

\section{PMH Principles in Practice:Three Examples Marathon FHT's High-Yield Approach to Risk Mitigation and Safety (HARMS): A program for safer opioid prescribing through systematic risk stratification and urine drug testing \\ Description}

This award-winning program (http://harmsprogram.ca/ awards), designed and implemented by the Marathon FHT to detect and treat opioid misuse, is a natural extension of the team's approach to delivering primary care that meets the needs of the communities served: Marathon, Pic Mobert and Biigtigong First Nations.

HARMS is a clinic-wide undertaking to make opioid prescribing safer for patients with chronic non-cancer pain. It requires mandatory urine drug testing (UDT) for all patients being prescribed opioids for chronic pain. Digital tools compile and analyze results to help physicians adjust treatment for patients who are monitored systematically based on their risk category. When HARMS identifies high-risk patients, their opioids are tightly controlled, while indications of addiction prompt treatment.

\section{... identifying and addressing addiction can facilitate secondary prevention and avoid health system costs.}

\section{Results}

Over a 12 -month period, nearly $20 \%$ of patients initially stratified as low risk had direct changes to management (escalation to higher-risk stream or addiction program, or a very small number of patients had their opioid prescriptions carefully tapered and stopped) based on UDT results.
Since the program's inception in 2014, the following occurred:

- The number of opioids dispensed by a patient's family physician decreased by $58 \%$.

- The number of new opioid prescriptions decreased by $29 \%$.

- A total of 20 to 30 patients are now receiving addiction treatment; prior to HARMS, there was none. The program currently serves between 80 and 100 patients.

Implementing HARMS also yields health system savings. Like a stress test signalling a heart condition, identifying and addressing addiction can facilitate secondary prevention and avoid health system costs. Further efficiencies ensue from HARMS: tests and testing are covered in the basket of services for which Marathon family physicians are remunerated under the Rural Northern Alternate Funding Model.

\section{Collaboration}

HARMS lead Dr. Ryan Patchett-Marble and family physicians Dr. Megen Brunskill and Dr. Nancy Fitch, members of the chronic pain and addiction management committee struck in 2014, say HARMS benefited from the FHT's strong and long culture of collaboration and its collective understanding of UDT as central to safe opioid management - not a widely held perspective or practice.

Developing and implementing the program required everyone to be on board: administrative staff, doctors, NPs, nurses, social workers and health promotion and chronic pain co-ordinators. Given time constraints and poor adherence to UDT guidelines ( $6 \%$ to $10 \%$ ), the design had to be practical and easy to use. Marathon's part-time pain coordinator did in-clinic training on UDT and Self-Report, Testing and Automated Reading Tool for Immunoassay Testing (STARTIT) before booking patients, conducting tests and collecting the data that START-IT interprets.

\section{Governance and management}

Dr. Sarah Newbery, a local physician since 1996, credits ongoing work to governance - establishing a strong board with clinical leadership and clear roles and accountability - as key to creating a high-functioning team and, over time, a PMH practice.

\section{Health information technology}

The HARMS program relies on digital health technology, specifically the START-IT tool that is installed on an office PC tablet. The coordinator and HARMS patients use it to record medication/drug use data along with the results 
of UDT immunoassay tests. With a keystroke, the information is compiled, interpreted and inserted into the electronic medical record (EMR).

\section{Continuity of care}

In a rural setting such as Marathon, team members work to fill service gaps and provide seamless care. Marathon has no long-term care facility or access to homecare nursing. In the local hospital, which has 10 acute and 12 chronic care beds, Marathon FHT physicians serve as medical staff and cover the 24/7 emergency service and in-patient care. They all do home visits and see each other's patients, ensuring that shared e-records are updated for information continuity.

\section{Community adaptability and social accountability}

The HARMS program started well before opioid addiction hit the headlines, testament to the FHT's deep understanding of the community and its challenges. HARMS facilitates compassionate care delivered without judgment; it identifies who is struggling and in need of treatment to manage their condition and symptoms and avoid addiction. The team works with each other's strengths; Dr. Patchett-Marble and his colleagues practise to meet all the patient's needs - biological, psychological, social and spiritual. Outreach efforts brought HARMS information sessions to both reserves. An annual patient survey on opioids was introduced; the latest showed that $64 \%$ of area patients considered opioids a problem in their community.

\section{Commitment to research and ongoing quality improvement}

The retrospective analysis on HARMS demonstrated its success in detecting addicted and high-risk patients and altering the management of their care. Dr. Patchett-Marble has since partnered with researchers in urban centres to secure funding for a large-scale multi-site study, a prospective trial that would be the first to address whether systematic UDT in patients with chronic non-cancer pain improves safety. The Marathon FHT was also an early adopter of integrating QI into practice. As a first-wave FHT, it tapped into QI support resources early, requesting funding for a part-time epidemiologist to embed QI and evaluation into the team's work.

\section{Family physician leadership}

Physician recruitment and retention in northern and rural communities are almost always difficult, but since its start in 1996, the Marathon FHT has enjoyed strong physician engagement and can report 20 years of being essentially free of physician shortages. Marathon FHT physicians are committed to the community and to each other. Their focus on "intraprofessional" care underpins a practice that is based on collegiality, trust and understanding. Many Marathon residents say their belief in the strength of local healthcare services was key to deciding to remain in the community or return to it after retiring elsewhere.

\section{Markham FHT's Eating Disorders Bridge Program Description}

The "Eating Disorders Bridge" Program is open to all Markham FHT patients who are on a wait list for a hospitalbased eating disorders program to which they must transfer when space becomes available. The program is run by an interprofessional team led by an NP working with a registered dietitian and a social worker. Combining their expertise, they work collaboratively to sustain and improve their patients' medical stability.

\section{Results}

The Eating Disorders Bridge Program objectives were all met and targets reached or exceeded (Table 1):

- Since $2017,100 \%$ of the 27 patients enrolled in the program had achieved and/or maintained medical stability when discharged from the FHT program.

- Some patients progressed so well that when specialized hospital treatment became available, they no longer needed it or required shorter stays, expediting care and freeing up space for other patients on the waiting list.

- Each integrated health professional had targets for the number of sessions they provided for each patient (Table 2). Examples from 2017 to 2018 are as follows: - a total of $48 \mathrm{NP}$ visits for 15 patients, meeting the target of $100 \%$ of visits as needed per patient, and

- a total of 31 social worker visits and 12 dietitian consultations for the 15 patients in the program that year, exceeding the target of at least one visit per patient before entry to the community program.

- Team members succeeded in not only identifying patients for immediate in-patient care but also liaising with service providers in other sectors and together eliminating barriers so that patients received the right care in the right setting, which means avoiding unnecessary emergency room (ER) visits.

\section{Comprehensive care and team cohesion}

Before the program was created, NP Kelly Van Camp had observed patients with eating disorders presenting with serious health issues, some as young as seven (Box 1). Facing lengthy waits for specialized treatment, they were becoming medically unstable and at high risk for harm. Sudden death is the biggest risk for patients with eating disorders.

Late in 2012, NP Van Camp and Markham Clinical Programs Manager Lisa Ruddy, RN, seized the opportunity to reduce that risk, improve care and health outcomes and 
provide more comprehensive services to patients suffering from a pernicious condition. They say the program would not exist without engaged clinicians who educated themselves further so that their patients not only survive the wait for specialized services but also arrive better able to benefit from them.

TABLE 1.

Markham FHT's eating disorders program: resources, EMR features and program targets

\begin{tabular}{|c|c|}
\hline Resources & EMR \\
\hline $\begin{array}{ll}\text { - } & \text { Registered dietitian + social } \\
\text { - } & \text { Norker } \\
\text { Nurse practitioner + registered } \\
\text { dietitian } \\
\text { - Social worker + nurse } \\
\text { practitioner } \\
\text { +/- Medical doctor }\end{array}$ & $\begin{array}{l}\text { - Search weight or body mass } \\
\text { index } \\
\text { - Search various diagnoses } \\
\text { - Search International } \\
\text { Classification of Diseases, Ninth } \\
\text { Revision or Tenth Revision codes } \\
\text { - Optimize billing/tracking } \\
\text { - Standardize documentation }\end{array}$ \\
\hline Patients & Community partners \\
\hline $\begin{array}{ll}\text { - } & \text { Existing diagnosis } \\
\text { - } & \text { Making the diagnosis } \\
\text { - } & \text { Preventing destabilization } \\
\text { - } & \text { Initiating treatment }\end{array}$ & $\begin{array}{l}\text { - Hospital-based emergency } \\
\text { department programs } \\
\text { - Community-based emergency } \\
\text { department programs } \\
\text { - Local mental health programs }\end{array}$ \\
\hline
\end{tabular}

$\mathrm{EMR}=$ electronic medical record; $\mathrm{FHT}=$ family health team

TABLE 2.

Markham FHT's eating disorders program: distribution of integrated health professional resources and accompanying counselling sessions

\begin{tabular}{l|l}
$\begin{array}{l}\text { FHT interprofessional healthcare } \\
\text { providers allocation }\end{array}$ & $\begin{array}{l}\text { Number of visits (April 1, 2017- } \\
\text { March 31, 2018) }\end{array}$ \\
\hline Nurse practitioner (0.08 FTE) & 84 visits for 16 patients \\
Social worker (0.06 FTE) & 69 visits for 15 patients \\
Registered dietitian (0.04 FTE) & 54 visits for 13 patients
\end{tabular}

FHT = family health team; FTE = full-time equivalent.

The program's design is streamlined and straightforward: the patient is diagnosed and a referral is sent to the hospitalbased eating disorders program and to the bridge program NP, who reviews it and, if appropriate, schedules patient assessments. The NP evaluates and monitors the patient's medical stability throughout and facilitates follow-up visits with the dietitian and social worker, who provide services based on the patient's care plan. If a patient's status deteriorates, it is addressed early on by the team or, if necessary, the patient is referred to acute care.
BOX 1.

Safe in his patient medical home: a young boy's experience

A young boy, a Markham family health team patient since his birth, was brought in because of increasingly concerning behaviour and was diagnosed with obsessive-compulsive disorder (OCD). He developed a serious eating disorder, managed by the nurse practitioner, social worker and dietitian, who supported him, his family and each other during and after the program. They created a multi-pronged care plan together, directed family to educational and counselling sessions and consulted Southlake Hospital on managing the patient's combined OCD and eating disorder.

The young patient progressed from being so ill he was pulled from school to becoming stable and transitioning easily to the hospital program. Arriving in a stronger condition, he was able to leave sooner than expected, weight restored. After a smooth journey for patients and providers alike, accessing seamless, integrated services, he returned, full circle, to his medical home and continuous care, which includes chronic disease management.

Measurement and continuous quality improvement Markham FHT's eating disorders program leverages many EMR features to generate data to track patient outcomes and evaluate program results.

The program tracks patients' weight loss and heart rates to help measure the percentage of program participants achieving or maintaining medical stability. It compiles data on the number of counselling sessions per integrated health professional to monitor progress against targets. Those targets - all met or exceeded - were achieved with an effective distribution of FHT resources, described below.

\section{Peterborough FHT: New services improve primary care access to an underserviced region Description}

In 2018, the Peterborough FHT offered two new options for primary care services to the approximately 7,000 residents without a family doctor or NP or whose primary care provider is outside Peterborough County ("unattached patients"). The Peterborough Virtual Care Clinic was launched in August in the city's downtown, and a new Peterborough FHT Clinic opened in September in Lakefield, Peterborough County.

The shortage of family physicians is a challenging problem in Peterborough County. There are no walk-in clinics and, for unattached patients, nowhere to go but the emergency department - a poor choice for patients, families and health providers and an expensive one for the system.

Patients accessing these new clinics receive continuing care and referrals to local supportive services until a physician becomes available. The virtual care clinic patients, either rural or urban, meet in person with a registered practical nurse who connects them with 
a family doctor through a secure video session. At the Lakefield clinic, an NP provides permanent residents from rural areas with continuity of care and seasonal residents with episodic care.

The Lakefield clinic operates from 9 a.m. to 4:30 p.m. four days a week from the Morton Community Healthcare Centre. The Centre's foundation donated $\$ 100,000$ over five years to help support the clinic's quest to improve access to health services. The virtual clinic operates part time three days a week, with expanded hours anticipated. The virtual clinic is a collaboration of the FHT, the City of Peterborough and the Virtual Family Physician Networks. It is a Central East Local Health Integration Network subregion project.

\section{Results}

Although still early days, the clinics have brought greater (and first-time) access to primary care services for many Peterborough residents:

- From September 10, 2018, to March 1, 2019, the combined number of visits to the two new clinics is close to 2,000 (Table 3).

- Since their launch, the clinics have provided almost 1,500 linkages and referrals to the FHT and community supports for previously unserved Peterborough residents (Table 4). Among them are lab services (576), specialist referrals (333) and an array of clinics and programs (i.e. smoking cessation, mindfulness and heart health) offered through the Peterborough FHT.

- Both clinics will help alleviate pressure on local ERs, felt most acutely in Lakefield throughout the cottage season.

- The data collection summary for the period September 10, 2018, to March 1, 2019, for the two clinics shows that these services are saving health system resources through better use of more appropriate, resource-efficient primary care outside the ER that helps end hallway medicine. The savings from ER department avoidance alone - which represents only a small fraction of overall system savings - is almost $\$ 130,000$ in less than six months (Table 5).

\section{Accessible care}

Peterborough FHT Executive Director Lori Richey says the clinics are important steps in closing the community's gap in care and meeting the FHT's end goal: a connection to a family physician for every resident in Peterborough.

The clinics generate a roster of permanent patients that help draw family doctors to the area. With a roster, they have immediate access to a practice with patients who have medical records from visits to the new clinics. Since the program was launched, two family doctors have joined the community; it is anticipated that 1,400 local residents will be connected to permanent primary care services over the next six months.
TABLE 3.

Number of first-time primary care visits to PVCC and to PFHTC

\begin{tabular}{|l|l|l|l|l|}
\hline Visit summary & PVCC & PFHTC & & Total \\
\hline Number of visits & 1,068 & 798 & 1,866 \\
\hline
\end{tabular}

PFHTC = Peterborough Family Health Team Clinic; PVCC = Peterborough Virtual Care Clinic

TABLE 4.

Number of visits avoided due to the services of the PVCC and of the PFHTC

\begin{tabular}{|c|c|c|c|}
\hline & PVCC & PFTHC & Total \\
\hline \multicolumn{4}{|c|}{ Where people would have gone for care had this clinic not been available } \\
\hline Nowhere & 164 & 343 & 507 \\
\hline $\begin{array}{l}\text { Other virtual } \\
\text { care clinic }\end{array}$ & 32 & & 32 \\
\hline Other walk-in & 215 & 117 & 332 \\
\hline $\begin{array}{l}\text { Emergency } \\
\text { department }\end{array}$ & 348 & 201 & 549 \\
\hline $\begin{array}{l}\text { Outside of city/ } \\
\text { country }\end{array}$ & 28 & & 28 \\
\hline Total & 787 & 661 & 1,448 \\
\hline
\end{tabular}

PFHTC $=$ Peterborough Family Health Team Clinic; PVCC = Peterborough Virtual Care Clinic.

TABLE 5.

Estimated system cost saving through emergency room diversions due to expanded primary care services to Peterborough's residents

\begin{tabular}{l|l|}
$\begin{array}{l}\text { Health system cost savings: } \\
\text { emergency room diversion }\end{array}$ & Estimated cost savings \\
\hline$\$ 234.00$ per ER visit* & $\$ 128,466.00$ \\
\hline
\end{tabular}

*Only includes nursing, diagnostic and therapeutic services and administration and overhead costs.

Dr. Tom Richard, a former chair of the Peterborough FHT and current Association of Family Health Teams of Ontario board director, acknowledges that the virtual care clinic and the NP-staffed clinic cannot match the comprehensive teambased services and relationships that rostered Peterborough FHT patients enjoy. But he says a Patient's Medical Home is an impossibility without access to services, timely or otherwise.

\section{Continuity of care}

Although the new clinics could be viewed as a band-aid or stop-gap, the Peterborough FHT has built in aspects of a Patient's Medical Home - such as continuity of care - where possible (for instance, maintaining consistent days of availability for virtual care doctors and linking the new clinics' patients to supports in 
the community and through the FHT). Each virtual doctor has a designated day of the week, and follow-up appointments for patients are booked so that they see the same doctor.

\section{Good Use of Health Information Technology: A Patient's Medical Home Foundation}

Introducing new digital solutions and using e-resources to fill gaps is good use of appropriate infrastructure. The PMH includes such infrastructure as a foundation because without underlying supports such as health information technology and integrated EMRs, the all-important PMH functions - accessible, continuous, comprehensive care - will not work properly or to full potential.

\section{Community and Social Accountability}

Ms. Richey reports that new patients cherish the clinics and what they bring to their lives. One such patient who had gone six years without seeing a family physician was having symptoms that made him think he had dementia. At the virtual clinic, he discovered the source of his problem: undiagnosed elevated blood pressure. He has since been treated and is now participating more fully in life. The executive director adds that patient and community surveys are already producing valuable data that are being analyzed to glean a better sense of the community's broad healthcare needs.

\section{Conclusion}

Family physicians and integrated teams of health professionals in Ontario are introducing innovations, embedding elements into their practice that exemplify the Patient's Medical Home. With PMH supports and foundations in place, they are delivering the quality of care enabled by strong PMH functions: accessible, comprehensive, continuous care centred on patients and families and responsive to a community's unique needs. Adhering to these principles not only improves patient experience, health outcomes and provider satisfaction, but care within a Patient's Medical Home also leads to fewer unnecessary hospital admissions and ER visits - system savings and better use of public resources. It creates the conditions for health system reform success (Levesque et al. 2015; Sikka et al. 2015; Starfield et al. 2005).

That success is inextricably tied to a strong primary care sector, appropriately funded, equipped and governed, in which teams built on trust deliver both high-quality care to patients and savings to the system. $\mathrm{HQ}$

\section{Acknowledgements}

The authors acknowledge and thank the following healthcare leaders for sharing their expertise and experiences: Marathon Family Health Team family physicians Dr. Sarah Newbery, Dr. Megen Brunskill, Dr. Nancy Fitch and Dr. Ryan PatchettMarble (HARMS program lead); Markham Family Health Team Clinical Programs Manager Lisa Ruddy, RN, and Nurse Practitioner Kelly Van Camp, Eating Disorders Bridge Program lead; and Peterborough Family Health Team Executive Director Lori Ritchey and AFHTO Board member Dr. Tom Richard, former chair of the Peterborough Family Health Team.

\section{References}

Aggarwal, M. and B. Hutchison. 2012. Toward a Primary Care Strategy for Canada. Ottawa, ON: Canadian Foundation for Healthcare Improvement.

Cavers, W.J., V.H. Tregillus, A. Micco and M.J. Hollander. 2010. Transforming Family Practice in British Columbia: The General Practice Services Committee. Canadian Family Physician 56(12): 1318-21.

College of Family Physicians of Canada. 2011. A Vision for Canada: Family Practice - The Patient's Medical Home. Retrieved October 15, 2019. <http://www.cfpc.ca/A_Vision_for_Canada/>.

Katz, A., N. Herpai, G. Smith, K. Aubrey-Bassler, M. Breton, A. Boivin et al. 2017. Alignment of Canadian Primary Care with the Patient Medical Home Model: A QUALICO-PC Study. Annals of Family Medicine 15(3): 230-36. doi:10.1370/afm.2059.

Levesque, J.-F., J.L. Haggerty, W. Hogg, F. Burge, S.T. Wong, A. Katz et al. 2015. Barriers and Facilitators for Primary Care Reform in Canada: Results from a Deliberative Synthesis across Five Provinces. Healthcare Policy 11(2): 44-57. doi:10.12927/hcpol.2016.24448.

MacCarthy, D. and M.J. Hollander. 2014. RISQy Business (Relationships, Incentives, Supports, and Quality): Evolution of the British Columbia Model of Primary Care (Patient-Centered Medical Home). Permanente Journal 18(2): 43-48. doi:10.7812/TPP/13-083.

Sikka, R., J.M. Morath and L. Leape. 2015. The Quadruple Aim: Care, Health, Cost and Meaning in Work. BMJ Quality \& Safety 24(10): 608-10. doi:10.1136/bmjqs-2015-004160.

Starfield, B., L. Shi and J. Macinko. 2005. Contributions of Primary Care to Health Systems and Health. Milbank Quarterly 83(3): 457-502. doi:10.1111/j.1468-0009.2005.00409.x.

\section{About the Authors \\ Leanne Clarke, BA, is the chief executive officer of the Ontario College of Family Physicians. She can reached by the following methods: phone: 416-867-1838; fax: 416-867-9990; mobile: 647-244-7966; and e-mail: Iclarke@ocfp.on.ca.}

Kavita Mehta, BScN, MBA, is the chief executive officer of the Association of Family Health Teams of Ontario. She can be reached by the following methods: phone: $647-234-8605$ ext. 212; mobile: 647-204-0212; and e-mail: kavita.mehta@afhto.ca. 